\title{
RECONSTRUÇÃo DA MATRIZ PEDAGógICA-PESQUISADORA: ENCONTRO COM NOSSOS PARADIGMAS
}

\author{
RECONSTRUCTION OF THE PEDAGOGICAL-RESEARCH MATRIX: \\ MEETING OUR PARADIGMS \\ RECONSTRUCCIÓN DE LA MATRIZ PEDAGÓGICA-INVESTIGADORA: \\ ENCUENTRO CON NUESTROS PARADIGMAS
}

Paula Pereira Scherre ${ }^{1}$

\begin{abstract}
RESUMO
Este artigo tem uma de suas origens no chamado de autores que indicam a necessidade de desenvolvermos a Educação, as formações docentes e a produção de conhecimento científico, com base na Complexidade e na Transdisciplinaridade. Tenho o objetivo de refletir sobre um caminho (trans)formativo de reconstrução de matriz pedagógica-pesquisadora, como tomada de consciência das raízes paradigmáticas subjacentes ao ser e ao fazer profissional, docente e pesquisador. Este encontro foi possível por meio da metodologia de formação e de pesquisa denominada 'Narrativa Autoformadora', fruto de um estudo de natureza qualitativa, sistematizada e teorizada ao longo do meu doutorado em Educação. Como resultado, temos a identificação da matriz vigente, em suas dimensões pedagógica e pesquisadora, o reconhecimento de suas bases no paradigma newtonianocartesiano e a abertura para a construção de outra matriz emergente sob o Paradigma da Complexidade e o Paradigma Educacional Emergente. Mesmo sabendo que os diferentes paradigmas continuarão coexistindo em mim, ter a consciência de como me influenciam me permite aprimorar meu ser e meu fazer profissional. Acredito que este tipo de processo (auto)formativo possibilita tomarmos as rédeas dos diferentes tipos e contextos de formação, nos empoderarmos de nossa história e projeto de vida, atribuirmos sentido ao que é aprendido e vivido, valorizarmos conhecimentos, aprendizagens e experiências, em contínuo diálogo com saberes disciplinares e teóricos. Almejo contribuir para que ambientes de aprendizagem (presenciais, virtuais e híbridos) possam ser espaços e tempos de (trans)formação, de autoconhecimento, de pesquisa, de autoria, de sentido, de criatividade e de produção de conhecimentos de si e conhecimentos científicos.
\end{abstract}

PALAVRAS-CHAVE: Matriz pedagógica-pesquisadora. Transdisciplinaridade. Complexidade. Educação.

\begin{abstract}
This abstract has its origins in the call of some authors who indicated the need for developing an Education, teacher-training, and scientific knowledge production, based upon the Complexity and Transdisciplinarity. My goal is to reflect on a (trans)formative path of reconstruction of the pedagogical-research matrix, developing awareness of the subjacent pragmatic roots of the professional being and doing, as well as teachers and researchers. This meeting was possible through the formative methodology and the research called 'Autoformative Narrative' resulting from a qualitative study which has been systematized and theorized throughout my $\mathrm{PhD}$ in Education. As a result, we have the present matrix identification, in its pedagogical and research dimensions, the recognition of its foundations in a Cartesian Newtonian paradigm and the openness to the building of another emerging matrix under the Complexity Paradigm, and the Emerging Educational Paradigm. Even knowing that the different paradigms will keep co-existing within me, being aware of how they influence me allows me to improve my professional being and doing. I believe this (Auto)formative process enables us to take control of the different formation types and contexts, to empower ourselves with our history and life project, to attribute sense to what is experienced and learned, to value knowledge, learning processes and experiences, in a continued dialogue with disciplinary and theoretical knowledge. I aim to contribute so that learning environments (in class, virtual, and hybrid) can be places and times of (trans)formation, self-

\footnotetext{
${ }^{1}$ Doutora em Educação pela Universidade Católica de Brasília. Integrante do Grupo de Pesquisa ECOTRANSD - Ecologia dos Saberes, Transdisciplinaridade e Educação. E-mail: pscherre@ gmail.com

Submetido em: 07/06/2016 - Aceito em: 21/09/2016.
}

\begin{tabular}{l|l|l|l|l|l|l} 
(C) Rev. Inter. Educ. Sup. & Campinas, SP & v.2 & n.2 & p.274-290 & maio/ago. 2016 & ISSN 2446-9424
\end{tabular}


knowledge, research, authorship, meaning, creativity, self-knowledge production, and scientific knowledge.

KEYWORDS: Pedagogical-research matrix. Transdisciplinarity. Complexity. Education.

\section{RESUMEN}

Este artículo tiene uno de sus orígenes en el llamado de autores que indican la necesidad de desarrollo de la Educación, de formaciones docentes y de producción de conocimiento científico, con base en la Complejidad y en la Transdisciplinariedad. Tengo el objetivo de reflexionar sobre un camino (trans)formativo de reconstrucción de la matriz pedagógica-investigadora, como toma de conciencia de las raíces paradigmáticas subyacentes al ser y quehacer profesional, docente e investigador. Este encuentro fue posible por medio de la metodología de formación y de investigación denominada 'Narrativa Autoformadora', fruto de un estudio de naturaleza cualitativa, sistematizada y teorizada a lo largo de mi doctorado en Educación. Como resultado tenemos la identificación de la matriz vigente, en sus dimensiones pedagógica e investigadora, el reconocimiento de sus bases en el paradigma newtoniano-cartesiano y la apertura para la construcción de otra matriz emergente sobre el Paradigma de la Complejidad y el Paradigma Educacional Emergente. Aun sabiendo que los diferentes paradigmas seguirán coexistiendo en mí, tener conciencia de cómo me inciden, me permite evolucionar personal y profesionalmente. Considero que este tipo de proceso (auto)formativo hace posible tomar las riendas de los diferentes tipos y contextos de formación, nos empoderamos de nuestra historia y proyecto de vida, le damos sentido a lo aprendido y vivenciado, valoramos conocimientos, aprendizajes y experiencias, en continuo dialogo con los saberes disciplinares y teóricos. Deseo contribuir para que los ambientes de aprendizaje (presenciales, virtuales e híbridos) puedan ser espacios en tiempos de (trans)formación, autoconocimiento, investigación, autoría, sentido, creatividad y producción de conocimientos personales y conocimientos científicos.

PALABRAS CLAVE: Matriz pedagógica-investigadora. Transdisciplinariedad. Complejidad. Educación.

\section{INTRODUÇÃO}

Desde 1996, a Lei de Diretrizes e Bases da Educação Nacional (LDB) define Educação como aquela que "abrange os processos formativos que se desenvolvem na vida familiar, na convivência humana, no trabalho, nas instituições de ensino e pesquisa, nos movimentos sociais e organizações da sociedade civil e nas manifestações culturais". Além disso, a partir da Constituição da República Federativa do Brasil, a LDB compreende que a Educação tem por finalidade o "[...] pleno desenvolvimento do educando, seu preparo para o exercício da Cidadania e sua qualificação para o trabalho” (BRASIL, 2015, p. 9).

Nesse mesmo período, foi lançada a publicação Educação um tesouro a descobrir (DELORS, 1998) - relatório da Comissão Internacional sobre Educação para o século XXI para a Organização das Nações Unidas para a Educação, a Ciência e a Cultura (UNESCO). Este documento destaca a Educação como elemento fundamental para que a Humanidade construa um ideal de paz, de liberdade e de justiça social. Propõe também que a Educação deve ser uma via para o desenvolvimento humano, baseada em quatro pilares: aprender a conhecer, aprender a fazer, aprender a viver juntos e aprender a ser:

[...] a Educação deve organizar-se em torno de quatro aprendizagens fundamentais que, ao longo de toda a vida, serão de algum modo para cada indivíduo, os pilares do conhecimento: aprender a conhecer, isto é adquirir os instrumentos da compreensão; aprender a fazer, para poder agir sobre o meio envolvente; aprender a viver juntos, a fim de participar e cooperar com os outros em todas as atividades humanas; finalmente aprender a ser, via essencial que integra as três

\begin{tabular}{l|l|l|l|l|l|l} 
(C) Rev. Inter. Educ. Sup. & Campinas, SP & v.2 & n.2 & p.274-290 & maio/ago. 2016 & ISSN 2446-9424 \\
\hline
\end{tabular}


precedentes. É claro que estas quatro vias do saber constituem apenas uma, dado que existem entre elas múltiplos pontos de contato, de relacionamento e de permuta (DELORS, 1998, p. 90 - grifo dos autores).

No livro Educação e Transdisciplinaridade II, o Centro de Educação Transdisciplinar da Escola do Futuro da Universidade de São Paulo (CETRANS) sugere mais dois pilares complementares, a saber: aprender a antecipar - "uma vez que não podemos mais nos permitir aprender pela destruição" - e aprender a participar através de envolvimento - "uma vez que soluções para os problemas não podem ser encontradas em 'torres de marfim do aprender' sem envolver a massa crítica da sociedade" (MELLO; BARROS; SOMMERMAN, 2002, p. 201). Entendem também que esses seis pilares constituem os elementos norteadores para o exercício efetivo da Transdisciplinaridade na Educação.

Agora, no ano de 2016, a UNESCO publicou um novo relatório que nos convida a repensar a Educação rumo a um bem comum mundial. Reforça as visões dos seus dois relatórios anteriores: 'Aprendendo a ser: o mundo da educação hoje e amanhã', de 1972, e 'Educação: um tesouro a descobrir', de 1996. Chama-nos a um diálogo inspirado em uma visão humanística da Educação e do desenvolvimento e propõe que seja baseado "nos princípios de respeito pela vida e dignidade humanas, igualdade de direitos, justiça social, diversidade cultural, solidariedade internacional e responsabilidade compartilhada, com vistas a construir um futuro sustentável" (UNESCO, 2016, p. 8). Destaca que são esses os aspectos fundamentais e necessários para a nossa humanidade comum.

Este relatório também esclarece implicações dessa visão humanista para a "definição de conteúdo de aprendizagem e as pedagogias utilizadas, bem como para o papel de professores e outros educadores" (UNESCO, 2016, p. 9) no mundo complexo em que vivemos, mais interconectado e interdependente. Dentre as implicações, destaco as necessidades de também vincularmos a Educação com o desenvolvimento social e cultural, que ela não exclua e nem marginalize, que desenvolva "valores de respeito pela vida e pela dignidade humanas" (UNESCO, 2016, p. 41) e valorize a aprendizagem ao longo da vida. Para tanto, ressalto a necessidade de o papel de professores e educadores ser o de "facilitar a aprendizagem com vistas ao desenvolvimento sustentável de todos" (UNESCO, 2016, p. 41), compreendendo a diversidade, sendo inclusivos, ajudando a proteger e melhorar o meio ambiente. Sendo assim, além do oferecimento de condições de vida e de trabalho "mais atraentes, motivadoras e estáveis, incluindo salários e perspectivas de carreira", o relatório frisa que a formação dos professores deve:

[...] em todos os níveis - do mais geral ao mais especializado - [...] integrar melhor a própria essência do espírito transdisciplinar: uma abordagem interdisciplinar capaz de permitir que nossos professores nos levem pelo caminho da criatividade e à racionalidade e de um humanismo de progresso e desenvolvimento compartilhados, com respeito por nosso patrimônio natural e cultural comum.

(UNESCO, 2016, p. 60) 
Rumo à perspectiva transdisciplinar da Educação, o autor Basarab Nicolescu (1997, s.p.) propõe que uma Educação viável deve gerar uma Educação integral do ser humano a ser "dirigida para a totalidade aberta do ser humano e não apenas para um de seus componentes". $\mathrm{O}$ autor percebe que esta dimensão integral necessita ser desenvolvida também na universidade, já que este é um lugar propício para uma Educação que atenda às exigências de nosso tempo. Compreende que deve ser direcionada a crianças, adolescentes e adultos. Pondera também que, infelizmente, a Educação atual ainda privilegia o intelecto e relativiza a sensibilidade e o corpo, e que:

Isso foi certamente necessário em determinada época para permitir a explosão do conhecimento. Mas se esse privilégio continuar nos arrastará para a lógica louca da eficiência pela eficiência, que só pode desembocar em nossa autodestruição. (NICOLESCU, 2000, p. 141-142).

Edgar Morin (2011) e Maria Cândida Moraes (2008a; 2010a) também criticam o excesso de fragmentação disciplinar existente na Educação e na ciência em geral. Comentam que isto pode nos impedir de ver, entender e enfrentar "os problemas mais importantes da vida, os problemas fundamentais da humanidade, os problemas cotidianos, normais, corriqueiros" (MORIN, 2011, p. 33). Porém, não significa negar ou eliminar disciplinas e, sim, expressar a necessidade de nutri-las e integrá-las para produzir conhecimentos. Destacam também a necessidade de contextualizar e religar os saberes e ressaltam que o que é aprendido deve fazer sentido tanto para quem aprende quanto para quem ensina.

Significa o oferecimento de uma Educação voltada para a formação integral do indivíduo, para o desenvolvimento da inteligência, do seu pensamento, da sua consciência, do seu espírito, capacitando-o para viver numa sociedade pluralista em permanente processo de transformação. Isso implica, além das dimensões cognitivas e instrumental, o trabalho, também, da intuição, da criatividade, da responsabilidade social, juntamente com os componentes éticos, afetivos, físicos e espirituais. Para tanto, a Educação deverá oferecer instrumentos e condições para o aluno aprender a aprender, aprender a pensar, a conviver e a amar. Uma Educação que o ajude a formular hipóteses, construir caminhos, tomar decisões, tanto no plano individual, quanto no plano coletivo. (MORAES, 1997, p. 211)

Tendo em vista as concepções apresentadas, vários autores e autoras recomendam o desenvolvimento da Educação, de formações docentes e de produção de conhecimento científico com base em outro paradigma diferente do paradigma tradicional newtonianocartesiano (MORAES, 2008a; MORIN, 2007; BATALLOSO NAVAS, 2010; NICOLESCU, 1999; D'AMBRÓSIO, 2001; ARNT, 2007; 2010; GALVANI; PINEAU, 2012; PAUL, 2013). Eles propõem um paradigma baseado nas perspectivas teóricas da Complexidade e da Transdisciplinaridade, de maneira a promover, em linhas gerais, "a religação entre os saberes, a religação entre sujeito e objeto, entre educador e educando, entre o local e o global, o desenvolvimento de um Pensamento Complexo, de atitude transdisciplinar e conhecimentos multidimensionais" (SCHERRE, 2015b, p. 21). 
Moraes (2015) compreende que, ao trabalharmos com a Transdisciplinaridade em Educação, começamos a praticar "uma ética da e para a vida capaz de reintegrar o cosmo, a matéria, o ser humano e a vida [...]" (MORAES, 2015, p. 30 - grifos da autora). Para isso, ao adotarmos uma epistemologia da complexidade, que nutre uma metodologia transdisciplinar, podemos produzir uma nova proposta de educação que reconheça, compreenda e valorize a diversidade humana, as relações culturais, a reciprocidade crítica. Tudo isto necessita ser feito para que possamos "enfrentar os principais desafios vividos no mundo contemporâneo, bem como os diversos dilemas educacionais que tanto nos afligem" (MORAES, 2015, p. 31).

Para tanto, a autora destaca a necessidade de "curar o interior do sujeito aprendente", de maneira que tanto nós, professores, como também nossos estudantes possamos "aprender a olhar mais atentamente para o que ocorre dentro de cada um", "promover o contato com sua própria essência [...] resgatar o autoconhecimento e o reconhecimento do outro" (MORAES, 2015, p. 31). Moraes percebe como necessário o desenvolvimento de metodologias que nos permitam conhecer-nos, como fruto da realidade e contexto em que vivemos e convivemos, e nos propiciem o reconhecimento de nossas experiências de vida, o questionamento de nossos padrões de conduta, por vezes destrutivos, de nossas intolerâncias. Além disso, se possível, nos levem à compreensão de que "o ser humano é presença e que a sua qualidade de energia é o amor. Amor como emoção central da história evolutiva humana, como fundamento biológico do fenômeno social (MATURANA, 2000), como modo de viver no respeito mútuo, na justiça e na solidariedade" (MORAES, 2015, p. 32).

De maneira breve, a Transdisciplinaridade, conforme proposta por Nicolescu (1999), é aquilo que está entre, através e além das disciplinas. É uma nova maneira de conceber o conhecimento - construído na interação entre sujeito e objeto - e uma nova visão de ser humano e de mundo - complexa, integradora, dialógica. Tem como seus eixos metodológicos: a Complexidade - baseada na concepção de Edgar Morin (2007) - e as noções de terceiro incluído e de níveis de realidade.

A Carta da Transdisciplinaridade (1994, p. 169) apresenta, em seu artigo $5^{\circ}$, que a visão transdisciplinar "é resolutamente aberta na medida em que ela ultrapassa o campo das ciências exatas devido ao seu diálogo e sua reconciliação, não somente com as ciências humanas, mas também com a arte, a literatura, a poesia e a experiência interior". De maneira complementar, a autora Rosamaria Arnt define a Transdisciplinaridade como sendo:

[...] uma postura do ser perante o conhecimento que vá além da disciplina, articulando ciência, artes, filosofia e tradições, reconhecendo a multidimensionalidade humana e os múltiplos Níveis de Realidade, permitindo a interconexão do ser com a natureza, com o outro, consigo mesmo, alicerçando a ética, conspirando e atuando, inclusive em Educação, pela comunhão a favor da vida. (ARNT, 2007, p. 12)

Também, de forma breve, a Complexidade é compreendida como "aquilo que é tecido junto" (MORIN, 2007, p. 13) e é inerente às pessoas, às relações, ao conhecimento, à vida. Propõe uma reforma do pensamento (MORIN, 2010a), via Pensamento Complexo, que religa \begin{tabular}{l|l|l|l|l|l|l}
\hline (c) Rev. Inter. Educ. Sup. & Campinas, SP & v.2 & n.2 & p.274-290 & maio/ago. 2016 & ISSN 2446-9424
\end{tabular} 
opostos complementares, que reconhece o ser humano como multidimensional e constituído por níveis de percepção que permitem compreender a realidade como sendo multidimensional, multirreferencial, constituída de vários níveis. Entre outras coisas, essa maneira de pensar também nos convida a perceber a causalidade circular das ações e relações; a compreender que o todo é ao mesmo tempo menor e maior do que a soma das partes; a reinserir o sujeito como inerente e importante parte do processo de conhecimento; a conceber que o método é construído ao caminhar e que deve estar atento e aberto às emergências do caminho (MORIN, CIURANA; MOTTA, 2009).

Com base nas várias aberturas epistemo-metodológicas respaldadas na Complexidade e na Transdisciplinaridade (SCHERRE, 2015a), percebi a possibilidade e a oportunidade de reconstruir minha matriz pedagógica-pesquisadora, no percurso do doutoramento em Educação. Senti a necessidade de fazer esse encontro com as raízes paradigmáticas que estavam subjacentes à minha matriz vigente até a entrada no doutorado, que constituía meu ser docente-pesquisador, desvelando suas bases no paradigma tradicional newtonianocartesiano e, assim, compreender o que causava tantas inquietações. A partir dessa tomada de consciência, abri tempo e espaço para uma reconstrução dessa matriz com base nas perspectivas paradigmáticas da Complexidade (MORIN, 2007) e do Paradigma Educacional Emergente (MORAES, 1997).

Cabe destacar que Moraes (1997) comenta sobre a importância de, nos momentos de formação inicial e continuada de estudantes e professores, também haver tempo e espaço para o estudo, pesquisa e compreensão das "relações lógicas existentes entre as dimensões ontológicas, epistemológicas e metodológicas que caracterizam os diversos paradigmas de ciência" (MORAES, 1997, p. 87). Avalia, ainda, que a falta de clareza das relações entre essas três dimensões "prejudica a qualidade da prática educacional de maneira mais adequada e congruente com os avanços da ciência" (MORAES, 1997, p. 87).

O percurso de reconstrução da matriz pedagógica-pesquisadora não foi somente teórico, mas realizado no diálogo entre teorias e elementos da experiência prática vivida, como formadora-pesquisadora, no curso de Formação dos Educadores para a Cidadania, em Horizonte/Ceará, no período de junho de 2012 a dezembro de 2013 (SCHERRE, 2013). Considero que vivi o que Moraes (2010b, p. 42) propõe para as ações formativas, com foco no SER, nas quais "teremos de estar prestando maior atenção ao seu FAZER, convidando-o, sempre que possível, à reflexão sobre sua ação, para que ele possa desenvolver sua autonomia, sua criatividade e sua capacidade de crítica".

Sendo assim, neste artigo tenho como objetivo refletir sobre essa reconstrução de matriz, abordando seus aspectos metodológicos. Isto é feito de maneira a inspirar a outros professores, pesquisadores e profissionais, das mais diversas áreas de conhecimento, a abrirem tempos e espaços para que processos de (trans)formação de seu ser e de seu fazer, propiciem tomadas de consciência sobre suas raízes paradigmáticas e possam ser empreendidos ao longo de seus caminhos formativos iniciais e/ou continuados.

\begin{tabular}{l|l|l|l|l|l|l} 
(C) Rev. Inter. Educ. Sup. & Campinas, SP & v.2 & n.2 & p.274-290 & maio/ago. 2016 & ISSN 2446-9424
\end{tabular}


Faço o convite de incluir e ir além das fronteiras dos cursos de Pedagogia ou dos demais processos de formação de professores, ao concordar com Moraes (2015, p. 33), quando a autora reconhece como educadores não somente os docentes e profissionais da educação, mas, sim, todos os cidadãos e cidadãs, pois a Educação é "um problema da sociedade inteira e de todas as instituições nos mais diversos âmbitos" e, assim, todos têm "o dever e a responsabilidade social de educar de forma coerente com as necessidades humanas e planetárias atuais".

\title{
ENCONTRO COM A MATRIZ, DIMENSÕES E PARADIGMAS
}

Vinculada às aberturas epistemológicas e metodológicas respaldadas nas teorias da Complexidade e da Transdisciplinaridade (SCHERRE, 2015a), senti-me convidada por Ecleide Furlanetto (2010a) a compreender os tempos e espaços de formação como também de (trans)formação para:

\begin{abstract}
(a) revisão, ampliação e transformação da matriz pedagógica; (b) integração entre dimensões pessoais e profissionais; (c) a apropriação, pelos professores, de seus processos de formação; (d) atribuição de sentido desta formação em sua história de vida; (e) pensamento sobre a aprendizagem docente, ou seja, aprendizagem passa a ser fundamental na idade adulta, tanto para formação inicial quanto para a continuada. (SCHERRE, 2015b, p. 14)
\end{abstract}

Com base nesse movimento de (trans)formação, ampliei o conceito de matriz pedagógica, apresentado por Furlanetto (2010b), de maneira a abarcar as minhas duas dimensões - pedagógica e pesquisadora - que estavam em formação e sendo, simultaneamente, pesquisadas. Assim, propus a matriz pedagógica-pesquisadora como sendo "meus arquivos existenciais que guardam registros sensoriais, emocionais, cognitivos, acessados quando me exerço docente e pesquisadora" (SCHERRE, 2015b, p. 332). Considero que foi um importante meio de autoconhecimento e de contato com questões visíveis e questões invisíveis e desconhecidas dos momentos e espaços de formação pelos quais passei, além de propiciar a integração entre dimensões pessoais, profissionais e científicas (FURLANETTO, 2003).

Para realizar o caminho de reconstrução da minha matriz pedagógica-pesquisadora, desenvolvi a metodologia de formação e pesquisa, de natureza qualitativa, denominada Narrativa Autoformadora (SCHERRE, 2015b). Criada por meio de sistematizações e teorizações a partir do vivido, respeitando minha própria maneira de conhecer, aprender e pesquisar, esta reconstrução foi, então, composta por quatro relatos: Relato 1: História de vida de formação e identificação da matriz vigente; Relato 2: Sistematização da experiência de docência e pesquisa; Relato 3: Construção da metodologia de formação e pesquisa; Relato 4: Síntese da matriz emergente e contribuições para outros processos formativos.

A seguir, apresento o foco de cada relato:

No relato 1 - que perpassou pela história de vida de formação e pela matriz pedagógica-pesquisadora vigente - o foco foi na identificação, interpretação e

\begin{tabular}{l|l|l|l|l|l|l} 
(C) Rev. Inter. Educ. Sup. & Campinas, SP & v.2 & n.2 & p.274-290 & maio/ago. 2016 & ISSN 2446-9424
\end{tabular}


compreensão da matriz vigente, analisando a perspectiva paradigmática tradicional subjacente e abrindo para as outras possibilidades paradigmáticas de reconstrução à luz da Complexidade e da Transdisciplinaridade.

No relato 2 - que abarcou as aprendizagens ao longo da Formação de Educadores para a Cidadania - o foco foi na identificação, interpretação e compreensão do que foi marcante e significativo no percurso formativo e investigativo para a reconstrução da matriz emergente.

No relato 3 - onde trabalhei a metodologia de formação e de pesquisa - o foco foi na interpretação e compreensão do caminho de formação e de pesquisa empreendido na tese, buscando identificar suas dimensões, compreender suas idas e vindas, as inquietações, explicações e aprendizagens em relação à pesquisa.

O relato 4 - composto pela síntese da matriz pedagógica-pesquisadora emergente teve como foco a interpretação e a compreensão da matriz que se constituiu a partir do percurso de formação e pesquisa, agregando o que levo das aprendizagens construídas e a síntese poética das minhas expressões poéticas inseridas nos relatos e nas palavras dos outros. Vejo nestas expressões poéticas um momento de síntese, de organizar e mostrar a essência de cada uma dessas partes. (SCHERRE, 2015b, p. 174).

Para efeitos deste artigo, comentarei sobre a matriz pedagógica-pesquisadora vigente - até a entrada no doutorado - e a emergente - após os encontros teóricos e vivenciais propiciados pelo período de doutorado - elaboradas nos relatos 1 e 4, respectivamente. Tecerei reflexões também sobre o desvelar paradigmático empreendido em cada uma delas.

$\mathrm{Na}$ expressão poética do relato 1, traduzi sua essência nas seguintes palavras (SCHERRE, 2015b, p. 177):

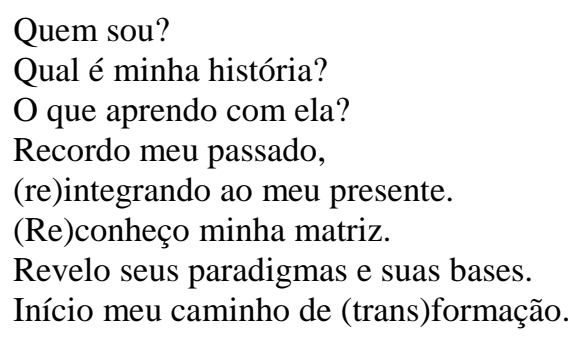

Por meio da escrita sobre a história de vida de formação, realizada no primeiro relato integrante da tese, realizei o reencontro com minhas escolhas formativas, com os momentos marcantes e históricos, com as relações sociais, pessoais e familiares que influenciaram nessas escolhas. Facilitou a tomada de consciência dos entrelaçamentos das motivações e inquietações formativas, sociais e existenciais. Também foi possível identificar os elementos constituintes de minha matriz em suas dimensões pedagógica e pesquisadora vigentes, até a entrada no doutorado, conforme apresento a seguir.

Matriz em sua dimensão pedagógica vigente construída, principalmente, a partir de experiências discentes, mas sem nenhuma formação profissional/acadêmica ou reflexão/estudo sobre a docência em si: 
Abarca compreensões como: eu, sendo docente, tinha que saber de tudo, ter resposta para tudo. Meu planejamento, bem detalhado, tinha que ser seguido à risca, porque senão eu não estaria sendo uma boa professora e se percebessem a minha insegurança, isso seria o "fim" perante os(as) estudantes. E se eu não soubesse responder alguma pergunta de algum(a) aluno(a)? Só de pensar me dava frio na barriga. Em uma disciplina bastante teórica, como a disciplina de Ergonomia 1, eu tinha que me ater sempre aos livros, aos textos, aos autores cientistas de referência. Eu não podia fugir do prescrito, do planejado, dos conhecimentos já indicados pelos especialistas, pois aquilo é que era o certo, o válido. Considerar outros tipos de conhecimentos? Isso nem me passava pela cabeça. Eu tinha que ser criativa, tinha que tornar minhas aulas interessantes, tinha que levar tudo pronto para ser trabalhado com os(as) estudantes. Neste período, mesmo tendo outras experiências pessoais com música, dança e artes, não percebia espaços, não sabia como eu poderia integrá-las em uma disciplina tão teórica, técnica e tão "longe" dessas outras áreas de conhecimento artístico. [...] Eu achava também que uma boa aula era a que eu falasse a maior parte do tempo, mostrando que eu sabia do que estava falando. Apesar de não estar satisfeita com toda essa situação, na época, eu não sabia como fazer diferente, nem se existia outro caminho pelo qual eu poderia ir. Eu sabia que era importante integrar toda aquela teoria da Ergonomia com a prática de um projeto ergonômico e dialogar com os estudantes sobre isso. Mas, para mim, as aulas se resumiam a aulas expositivas, resenhas de textos, provas, elaboração de projeto, apresentação e avaliação. Na orientação dos projetos dos alunos, eu tentava fazer de maneira detalhada, individual, atenciosa, tanto no material que eu entregava por escrito, quanto nas orientações presenciais com cada grupo separadamente. Eu gostava muito disso e sempre me recordava dos professores da graduação que fizeram isso comigo nos projetos que desenvolvi e nas orientações que presenciei em casa entre minha mãe e seus orientandos. Eu não sabia, nem conseguia pensar fora disso ou mesmo em outras possibilidades, ou até mesmo saber o porquê que eu fazia assim e o porquê que isso me trazia tanta insatisfação. Mas eu tinha certeza de que eu não estava me sentindo bem, que essa maneira de ser docente não me agradava e que me trazia sofrimento. Tive muitas dificuldades nesse processo e terminei o mestrado decidida a não dar mais aulas, a não emendar meus estudos com o doutorado e que continuaria trabalhando em equipes e atuando nas áreas de Ergonomia e design. (SCHERRE, 2015b, p. 332-333).

Matriz em sua dimensão pesquisadora vigente construída, principalmente, a partir de estudos no mestrado acadêmico:

Algumas das compreensões que trago comigo são: a pesquisa deve ser realizada a partir de um método definido, por exemplo, para uma intervenção ergonômica em contexto de trabalho, utilizamos o método de Análise Ergonômica do Trabalho (AET); para o estudo do uso e da navegação em interfaces gráficas, utilizamos a Tecnologia de Avaliação e (Re)Concepção de Interfaces Gráficas (TAI); a pesquisa é algo externo ao pesquisador e deve primar pela clareza de conceitos e referencial teórico, de problemas de pesquisa e objetivos; deve primar pelo detalhamento da metodologia, das técnicas e instrumentos utilizados; deve ser clara, explícita e ética com os participantes; pode integrar dados qualitativos e quantitativos; deve ter flexibilidade em se adequar ao contexto de pesquisa, de acordo com a demanda, mas, no momento de comparar usos e desempenhos de navegação e elaboração das recomendações de melhoria para a interface gráfica analisada, por exemplo, os procedimentos e instrumentos devem se manter os mesmos. Trago também comigo, importância de se considerar, em estudos e projetos, a lógica do usuário na (re)concepção de interfaces gráficas, pois a lógica do designer e do cliente/demandante são diferentes da lógica daquele(a) que irá realmente utilizar este produto; e que, por meio da análise ergonômica da navegação, dos estudos da usabilidade e da acessibilidade, eu posso inserir os usuários no processo de (re)concepção de interfaces gráficas. (SCHERRE, 2015b, p. 333). 
Autores como Behrens (2011) e Luckesi (2003) lembram que toda a prática docente é influenciada por algum tipo de paradigma científico. De acordo com Morin, um paradigma se constitui como o tipo relação lógica (indução, conjunção, disjunção, exclusão) que está subjacente à organização do pensamento. São "princípios ocultos que governam nossa visão das coisas e do mundo sem que tenhamos consciência disso" (MORIN, 2007, p. 10).

Sendo assim, no diálogo produzido, via relato 1, dessas dimensões da minha matriz com as leituras de autores como Behrens (2011), Luckesi (2003), Furlanetto (2010b), Moraes (1997), compreendi que o paradigma tradicional newtoniano-cartesiano estava subjacente às minhas concepções presentes em minha matriz, pois era:

\begin{abstract}
centrado no uso da razão e da experimentação como únicas formas de conhecimento completas e válidas, voltada para a reprodução do conhecimento científico, organizado pela lógica das disciplinas, fragmentado, ordenado e classificado. Nessa perspectiva, o professor considera o conhecimento como uma verdade préestabelecida, apresenta o conteúdo para os estudantes de maneira pronta e acabada, de forma linear, e busca repassar esses conhecimentos para eles repetirem e reproduzirem ao realizarem as tarefas propostas. Neste tipo de abordagem tradicional, a ênfase está predominantemente no ensinar, com base na linguagem da certeza e da verdade, negando a ambiguidade e a complexidade, e metodologicamente se caracteriza, em geral, por aulas expositivas e por demonstrações que o professor realiza em sala. Este mesmo paradigma, como inspirador da ciência moderna, também foi influenciador da minha matriz em sua dimensão pesquisadora, pois está presente em minha matriz, até então, o conceber a pesquisa como separada da vida do pesquisador; o ver sujeito (pesquisador) e objeto de estudo também separados e isolando o sujeito do processo de pesquisa e conhecimento; o encaixar a realidade e o objeto de estudo em um método definido previamente. (SCHERRE, 2015b, p. 333-334)
\end{abstract}

Toda a prática docente e de pesquisa é influenciada por um paradigma científico, que leva as pessoas a conhecerem, pensarem e agirem de acordo com paradigmas inscritos culturalmente e, ainda, que irriga e controla nosso pensamento consciente (MORIN, 2007). Por isso, a partir dos estudos teóricos e das experiências de docência e de pesquisa vividas, me propus, consciente e intencionalmente, a 'iniciar' uma transição paradigmática em minha matriz. Quando digo iniciar, é porque a espiral evolutiva de pesquisa, aprendizagem e (trans)formação continua, mesmo após a finalização deste período de formação em nível de pós-graduação.

Conforme comentei na introdução deste artigo, vários autores apontam para a necessidade de desenvolvermos a Educação, as formações docentes e a produção de conhecimento científico a partir de um paradigma baseado nas perspectivas da Complexidade e da Transdisciplinaridade. Sendo assim, me abri para o estudo das propostas do Paradigma da Complexidade (MORIN, 2010b) e do Paradigma Educacional Emergente (MORAES, 1997).

Ao perceber que o paradigma da simplificação vigente na ciência moderna, denominado tradicional newtoniano-cartesiano - baseado nos princípios da disjunção, da

\begin{tabular}{l|l|l|l|l|l|l} 
(C) Rev. Inter. Educ. Sup. & Campinas, SP & v.2 & n.2 & p.274-290 & maio/ago. 2016 & ISSN 2446-9424
\end{tabular}


fragmentação, da simplificação -, não dava mais conta de resolver os novos desafios da civilização contemporânea, Morin $(2007$; 2010b) propôs o Paradigma da Complexidade. Tal paradigma é orientado por lógicas de religação, unidade-diversidade, disjunção-união, análise-síntese, parte-todo, simplificar-complexificar. Convida-nos a desenvolver um pensar complexo, que, em linhas gerais, articula, relaciona e contextualiza; que está aberto ao inesperado e a rever teorias e ideias; que reconhece os fenômenos como multidimensionais; que respeita diferenças; que reconhece a incompletude e a incerteza; que reconhece a causalidade circular; que desenvolve sua própria autocrítica; que reconhece a interação entre sujeito e objeto e convida o sujeito a se inserir no processo de conhecimento; que comporta o erro e a ilusão; que reconhece disciplinas e ideias como tecidos em conjunto.

De maneira complementar, o Paradigma Educacional Emergente (MORAES, 1997) nos revela "um modelo educacional capaz de gerar novos ambientes de aprendizagem, em que o ser humano fosse compreendido em sua multidimensionalidade como ser indiviso em uma totalidade, com seus diferentes estilos de aprendizagem e suas distintas formas de resolver problemas" (MORAES, 1997, p. 17). A autora o concebe a partir do paradigma científico gerado com base "na teoria da relatividade, na teoria da física quântica e em suas implicações na filosofia da ciência e nas implicações na área educacional" (MORAES, 1997, p. 19). Caracteriza-o como construtivista, interacionista, sociocultural, transcendente (MORAES, 1997, p. 197-205) e afetivo (MORAES, 2008b, p. 295), conforme detalhado no Quadro 1:

QUADRO 1. Dimensões do Paradigma Educacional Emergente

\begin{tabular}{|c|c|}
\hline Dimensão & Descrição \\
\hline Construtivista & $\begin{array}{l}\text { O pensamento não tem fronteiras, constrói, reconstrói. O centro decisório do processo de } \\
\text { aprendizagem está no educando, que organiza suas experiências de aprendizagem, que } \\
\text { constrói seu conhecimento na ação no mundo, de acordo com suas necessidades e situações } \\
\text { que ocorrem, e o faz de modo diferente. Valoriza os processos. Tudo está em } \\
\text { interdependência, conectado, interligado. O processo é mais importante que o produto. } \\
\text { Criamos o mundo com base em nossa experiência, em nossa forma de observar, de olhar e } \\
\text { de apreender a realidade. Alunos e professores são investigadores em busca de um } \\
\text { conhecimento mais profundo e ampliado, nos quais aprimoram suas formas de aprender e de } \\
\text { ensinar, baseados no interesse e no prazer da produção do conhecimento. Não existe saber } \\
\text { pronto e acabado. Estamos envolvidos em um processo constante de construção de } \\
\text { conhecimento. O conhecimento científico não pode alcançar a certeza absoluta e final, cada } \\
\text { um pode aprimorar e ampliar os saberes existentes. A ciência e o conhecimento científico } \\
\text { sempre serão constituídos de afirmações aproximadas e de teorias provisórias. }\end{array}$ \\
\hline Interacionista & $\begin{array}{l}\text { Sujeito e objeto são organismos vivos, abertos, naturais e estão em interação e } \\
\text { interdependência entre si e o meio. Os fenômenos são multidimensionais e sujeito e objeto } \\
\text { estão em relação, em troca de energia, matéria e informação. A aprendizagem do aluno só } \\
\text { ocorre na medida em que ele age sobre os conteúdos específicos e altera suas próprias } \\
\text { estruturas. Percebe que ambos professores e alunos, ensinam e aprendem. Incentiva } \\
\text { trabalhos em equipe, espontaneamente constituídas. As salas de aula são vistas como } \\
\text { espaços de interação, de experimentação, de movimentação, de criação e de construção de } \\
\text { suas próprias obras. }\end{array}$ \\
\hline Sociocultural & $\begin{array}{l}\text { O conhecimento é construído em interação também com o mundo físico, social e cultural, } \\
\text { no contato com os símbolos, com os outros. O social é condição para que o sujeito } \\
\text { desenvolva sua capacidade de individuação e seu papel como integrante de uma construção } \\
\text { coletiva do social. Promove a integração com o seu contexto, com a sua realidade, que ele }\end{array}$ \\
\hline
\end{tabular}

\begin{tabular}{l|l|l|l|l|l|l} 
(C) Rev. Inter. Educ. Sup. & Campinas, SP & v.2 & n.2 & p.274-290 & maio/ago. 2016 & ISSN 2446-9424
\end{tabular} 


\begin{tabular}{|l|l|}
\hline Transcendente & possa pensar, refletir, agir sobre essa realidade. \\
\hline Afranscender significa ir mais além, ultrapassar, superar. Realidade interna e externa do \\
sujeito como integrantes de uma mesma unidade, que também tem uma dimensão humana, \\
mas também uma dimensão espiritual e que o "espírito desempenha um papel ativo e \\
organizador, essencial para o desenvolvimento da ação e para a construção do \\
conhecimento". (MORAES, 1997, p. 205)
\end{tabular}

Fonte: Elaborado pela autora a partir dos escritos de Moraes (1997, p. 197-205; 2008b, p. 295).

Com base nesse paradigma educacional proposto, Moraes entende a Educação como sendo "mediadora de um novo diálogo do homem consigo mesmo, com a sociedade e com a natureza". Esta deve propiciar a criação de ambientes de aprendizagem que abram espaço de diálogo entre o mundo externo e interno de cada um, que promovam o desenvolvimento do equilíbrio pessoal, a realização de "práticas integradoras corpo-mente-cérebro-espírito" (MORAES, 1997, p. 206). Além disso, promover a expressão da solidariedade, cooperação, compaixão entre os seres humanos, com respeito às diferenças, à diversidade de seres $\mathrm{e}$ culturas, "visando maior harmonia no mundo em que vivemos" (MORAES, 1997, p. 207).

Retomando a reconstrução da matriz, a partir do diálogo entre os estudos teóricos realizados e as aprendizagens constituídas a partir das experiências de docência e de pesquisa vividas, apresentei, no quarto relato da tese, a síntese da matriz emergente e também a reunião das expressões poéticas, presentes no início de cada relato.

A essência desse relato quatro foi expressa da seguinte maneira (SCHERRE, 2015b, p. 331):

\footnotetext{
O que levo leve?

O que leve levo?

religo partes, incorporo, agrego, levo

leve integro minhas aprendizagens

ao todo da minha matriz

dialogando com o passado presente

recriando, aprendendo,

docente-pesquisadora... humana

me (trans)formando no aqui e agora

rumo a um presente futuro.
}

A matriz emergente, em cada uma de suas dimensões, foi assim sistematizada:

Matriz em sua dimensão pedagógica emergente abarca compreensões como: eu, sendo docente, sou eterna aprendiz, não tenho que saber tudo, mas tenho que saber bem o que quero falar e abordar em sala de aula presencial/virtual. Sim, continuo achando necessário o planejamento de aula e o domínio do conteúdo, mas o percebo com abertura ao diálogo, à escuta, à flexibilidade, às emergências. Por meio do acordo de convivência no início da aula, parte dessa escuta e adaptações podem ser feitas. Vejo também a oportunidade das avaliações contínuas serem oportunidade de 
aprendizagem para mim e para os estudantes e também de readequação do que foi planejado. Continuo considerando o estudo da palavra dos autores, dos documentos de referência, como algo importante, mas desde que sejam integrados e dialogados com as palavras de cada um(a), com suas experiências, conhecimentos, expectativas e histórias de vida. Compreendo que isso deva ser feito de maneira que os temas a serem estudados e os projetos a serem elaborados façam sentido para os estudantes e tenham relação com suas buscas formativas e existenciais. Percebo-me com mais condições de escutar e de dialogar, caminhando para além do "tagarelar" e do reproduzir as ideias dos outros. (SCHERRE, 2015b, p. 339-340)

Matriz em sua dimensão pesquisadora emergente abarca compreensões como: eu, sendo pesquisadora, que busca o rigor conceitual e metodológico das pesquisas que desenvolvo, estou aberta a integrá-los com as histórias de vida, conhecimentos experienciais, tradições, arte, filosofia. Pesquisa com tempo para contemplar, para meditar, para fazer a escuta do que é externo e interno. Pesquisa que respeite, escute, reflita e expresse os caminhos construídos e não tentando encaixar a realidade e objeto pesquisados dentro de uma metodologia predefinida e imutável; e que reflita e reconheça sua provisoriedade e seu inacabamento. Sinto-me aberta a realizar e acompanhar pesquisas sobre as experiências e conhecimentos dos outros, mas também a orientar formações e pesquisas sobre conhecimento e aprendizagens do sujeito que aprende, que está em formação; a acompanhar e orientar outras pesquisas onde pesquisador e pesquisado sejam a mesma pessoa. Vejo-me aberta ao diálogo e ao tecido conjunto das áreas de conhecimento, ao que está para além, através e entre as disciplinas, entrelaçando a vida, a natureza, as pessoas. (SCHERRE, 2015b, p. 340)

Quero aqui destacar que, apesar de eu ter, a todo o momento, distinguido essas duas dimensões da minha matriz humana, compreendo que elas estão interligadas, entrelaçadas e imbricadas. Reconheço-me, ao mesmo tempo, como docente-pesquisadora, pois, em minha docência, a pesquisa está e estará sempre presente. Via dimensão ontológica da Complexidade, que nos traz a ideia da multidimensionalidade humana (ARNT, 2010; MORAES, 2008a; MORIN, 2000), entendo que o ser humano é, ao mesmo tempo, cultural, social, espiritual, físico, biológico, político, cognitivo, emocional etc. Percebo também que:

em cada um dos ambientes profissionais e acadêmicos nos quais convivo e me exerço, eu aciono, pelo menos, uma dimensão da minha matriz, eu aciono os arquivos existenciais, ou seja, os registros sensoriais, cognitivos e emocionais condizentes com cada uma dessas atividades. [...] Seguindo este pensamento, acredito que acionamos outras dimensões de nossa matriz em cada meio que vivemos e convivemos, ou seja, acessamos outras multidimensões de nossa matriz humana, em cada contexto onde nós nos exercemos como seres humanos que somos. (SCHERRE, 2015b, p. 206)

Além disso, reconheço que, para cada ambiente profissional no qual eu estiver envolvida, em cada atividade a ser desenvolvida em ambiente universitário, levarei minha matriz, meus paradigmas e minhas aprendizagens, sempre abertos a conhecer e a aprender "coisas" novas. Compreendo que matriz, paradigmas e aprendizagens são permeáveis às interações com as outras pessoas, à escuta sensível do outro e da realidade, em sua multidimensionalidade; e também ao compartilhar construções, projetos, caminhos; à abertura às emergências e a autoria das pessoas envolvidas. São inerentemente inacabados, incompletos, em constante construção e vir-a-ser. 
Tenho conhecimento de que também meus paradigmas antigos e novos estarão sempre presentes. Mesmo que eu tenha feito todo esse movimento formativo, todos eles fazem parte de mim, ao mesmo tempo, fazem parte das minhas memórias que, na visão de Pineau (2014, p. 109), não é algo inerte e sim dinâmico, passível, assim, de conectar as três dimensões do tempo: passado, presente e futuro. Além disso, o nosso corpo é uma "memória orgânica que registra tudo".

Mas, o que percebo como importante, de todo esse processo, é ter a consciência desses paradigmas e de como eles me influenciam e, assim, a partir de caminhos (auto)reflexivos, (auto)formativos e (auto)críticos, poder continuar a estabelecer o diálogo entre meu ser e meu fazer, em busca de aprimorar minhas práticas profissionais, como docente, pesquisadora e designer (além de todas as outras que vierem futuramente). Cabe fazer um lembrete que a (auto)formação (ação do eu) deve estar sempre em constante diálogo com os demais polos hetero (ação dos outros) e eco (ação do ambiente) que também fazem parte de todos os processos formativos, revelando um movimento tripolar de formação (GALVANI; PINEAU, 2012).

\section{CONSIDERAÇÕES FINAIS, SEMPRE ABERTAS E PROVISÓRIAS}

Acredito que a realização de processos (auto)formativos deste tipo, no qual nos (trans)formamos e, ao mesmo tempo, nos investigamos, tomando consciência de nossa matriz, do que nos constitui - enquanto pessoa, profissional, docente, pesquisador -, e do(s) paradigma(s) subjacente(s) permite, a nós mesmos, tomar as rédeas de nossa formação, empoderar-nos de nossa história e projeto de vida, aprimorar nossa prática, nosso ser e fazer. Permite-nos atribuir sentido ao que é aprendido e vivenciado, a tomar consciência de nossas crenças mais profundas que, historicamente, têm suas bases em uma Educação disciplinar, fragmentada, que privilegia o desenvolvimento cognitivo/intelectual e a transmissão de informações.

Trago a esperança de contribuir com outros processos formativos, de maneira que eles levem em consideração, em suas teorias e práticas, os seres humanos que se formam e que valorizem suas histórias, conhecimentos, origens, aprendizagens e experiências. Espero que sejam criados espaços e tempos para que saberes disciplinares e teóricos dialoguem aberta e sensivelmente com todos esses outros conhecimentos que as pessoas em formação trazem consigo e produzem. Almejo que esses ambientes de aprendizagem (presenciais, virtuais e híbridos) sejam, ao mesmo tempo, de (trans)formação, de autoconhecimento, de pesquisa, de autoria, de sentido, de criatividade e de produção de conhecimentos de si e conhecimentos científicos. 


\section{REFERÊNCIAS}

ARNT, Rosamaria de Medeiros. Docência transdisciplinar: em busca de novos princípios para ressignificar a prática educacional. 2007. 266 f. Tese (Doutorado). Pontifícia Universidade Católica de São Paulo, São Paulo, 2007. Disponível em: <http://www.sapientia. pucsp.br/tde busca/arquivo.php?codArquivo=4742 > . Acesso em: 5 mai. 2016.

ARNT, Rosamaria de Medeiros. Formação de professores e didática transdisciplinar: aproximações em foco. In: MORAES, Maria Cândida; BATALLOSO, Juan Miguel. (Org.). Complexidade e Transdisciplinaridade em Educação: Teoria e Prática Docente. Rio de Janeiro: Wak Editora, 2010. p. 109-136.

BEHRENS, Marilda Aparecida. O paradigma emergente e a prática pedagógica. 5. ed. Petrópolis: Editora Vozes, 2011.

BRASIL. Lei de Diretrizes e Bases da Educação Nacional: Lei no 9.394, de 20 de dezembro de 1996, que estabelece as diretrizes e bases da Educação nacional. 11. ed. Brasília: Câmara dos Deputados, Edições Câmara, 2015. Disponível em: $<$ http://www2.camara.leg.br/documentos-e-pesquisa/edicoes/paginas-individuais-doslivros/lei-de-diretrizes-e-bases-da-educacao-nacional>. Acesso em: 1 jun. 2016.

BATALLOSO NAVAS, Juan Miguel. Didáctica desconstrutiva y complexidade: algunos principios. In: MORAES, Maria Cândida; BATALLOSO NAVAS, Juan Miguel (Orgs). Complexidade e Transdisciplinaridade em Educação: teoria e prática docente. Rio de Janeiro: Wak editora, 2010. p. 63-108.

CARTA DA TRANDISCIPLINARIDADE, 1994. In: UNESCO. Educação e Transdisciplinaridade. UNESCO, 2000. p.167-171. Disponível em: < http://unesdoc.unesco.org/images/0012/001275/127511por.pdf >. Acesso em: 9 mai. 2016.

D’AMBROSIO, Ubiratan. Transdisciplinaridade. 2. ed. São Paulo: Palas Athenas, 2001.

DELORS, J. (Org.). Educação um tesouro a descobrir: relatório para a UNESCO da Comissão Internacional sobre Educação para o século XXI. Brasília: Cortez Editora. MEC/UNESCO, 1998.

FURLANETTO, Ecleide. Como nasce um professor?: uma reflexão sobre o processo de individuação e formação. São Paulo: Paulus, 2003.

FURLANETTO, Ecleide. Processos de (trans)formação do professor: diálogos transdisciplinares. EccoS - Revista Científica. São Paulo, v. 12, n. 1, jan/jun. 2010a, p. 85101. Disponível em: 〈http://www.redalyc.org/pdf/715/71518577005.pdf >. Acesso em: 9 mai. 2016.

FURLANETTO, Ecleide. Formação e transdisciplinaridade: o encontro com a experiência. In: TORRE, S., PUJOL, M. A., RAJADLE, N., BORJA, M. (Coords). Innovación y Creatividad. Barcelona: GIAD, 2010b. CD-ROM. Disponível em: <http://www.increa. uneb.br/anais/increa2/forlaneto.pdf>. Acesso em: 9 maio.2016. 
GALVANI, Pascal; PINEAU, Gaston. Experiências de vida e formação docente: religando os saberes - um método reflexivo e dialógico. In: MORAES, Maria Cândida; ALMEIDA, Maria Conceição de (Orgs.). Os sete saberes necessários à educação do presente: por uma Educação transformadora. Rio de Janeiro: Wak editora, 2012. p. 205-226.

LUCKESI, Cipriano Carlos. Formação do educador sob uma ótica transdisciplinar. Revista ABC EDUCATIO, v. 4, n. 29, nov. 2003, p. 1-12. Disponível em: <http://www.luckesi. com.br/textos/abc_educatio/abceducacio_29_formacao_do_educador.pdf $>$. Acesso em: 9 maio. 2016.

MELLO, Maria F. de; BARROS, Vitória Mendonça de; SOMMERMAN, Américo (Orgs.). Educação e Transdisciplinaridade II. São Paulo: Editora Triom, 2002. Disponível em: <http://unesdoc.unesco.org/images/0012/001297/129707por.pdf >. Acesso em: 5 mai. 2016.

MORAES, Maria Cândida. O paradigma educacional emergente. Campinas: Papirus, 1997.

MORAES, Maria Cândida. Ecologia dos saberes, Complexidade, Transdisciplinaridade e Educação: novos fundamentos para iluminar novas práticas educacionais. São Paulo:

Antakarana/WHN - Willis Harman House, 2008a.

MORAES, Maria Cândida. Pensamento eco-sistêmico: educação, aprendizagem e cidadania no século XXI.

2. ed. Petrópolis: Vozes, 2008b.

MORAES, Maria Cândida. Complexidade e Transdisciplinaridade na formação docente. In: MORAES, Maria Cândida; BATALlOSO, Juan Miguel. (Orgs.). Complexidade e Transdisciplinaridade em Educação: teoria e prática docente. Rio de Janeiro: Wak editora, 2010a, p. 175-206.

MORAES, Maria Cândida. Ambientes de aprendizagem como expressão de convivência e transformação. In: MORAES, Maria Cândida; BATALLOSO, Juan Miguel. (Orgs.).

Complexidade e Transdisciplinaridade em Educação: teoria e prática docente. Rio de Janeiro: Wak editora, 2010b p. 21-62.

MORAES, Maria Cândida. Transdisciplinaridade, criatividade e educação: fundamentos ontológicos e epistemológicos. Campinas: Papirus, 2015.

MORIN, Edgar. Os sete saberes necessários à educação do futuro. Tradução de Catarina Eleonora F. da Silva e Jeanne Sawaya. 2. ed. São Paulo: Cortez Editora, 2000.

MORIN, Edgar. Introdução ao Pensamento Complexo. Tradução de Eliane Lisboa. 3. ed. Porto Alegre: Sulina, 2007.

MORIN, Edgar. A cabeça bem feita: repensar a reforma e reformar o pensamento. Tradução de Eloá Jacobina. 17. ed. Rio de Janeiro: Bertrand Brasil, 2010a.

MORIN, Edgar. Ciência com consciência. Tradução de Maria D. Alexandre e Maria Alice Sampaio Dória. 14. ed. Rio de Janeiro: Bertrand Brasil, 2010 b. 
MORIN, Edgar. Para um pensamento do sul. In: Para um Pensamento do Sul: diálogos com Edgar Morin. Rio de Janeiro: SESC, Departamento Nacional, 2011, p. 8-21. Disponível em: $\langle$ http://newpsi.bvs-psi.org.br/eventos/ANAIS-para-um-Pensamento-do-Sul-Marco2011.pdf >. Acesso em: 5 maio. 2016.

MORIN, Edgar; CIURANA, Emilio-Roger; MOTTA, Raul Domingo. Educar na era planetária: o pensamento complexo como método de aprendizagem pelo erro e incerteza humana. Tradução de Sandra Trabucco Valenzuela. 3. ed. São Paulo: Cortez Editora, 2009.

NICOLESCU, Basarab. A evolução transdisciplinar da universidade: Condição para o Desenvolvimento Sustentável, 1997. Disponível em: 〈http://cirettransdisciplinarity.org/bulletin/b12c8por.php\#note>. Acesso em: 5 maio. 2016.

NICOLESCU, Basarab. O manifesto da Transdisciplinaridade. Tradução de Lucia Pereira de Souza. São Paulo: Editora Triom, 1999.

NICOLESCU, Basarab. Um novo tipo de conhecimento - Transdisciplinaridade. In: UNESCO. Educação e Transdisciplinaridade. UNESCO, 2000. p.129-142. Disponível em: 〈http://unesdoc.unesco.org/images/0012/001275/127511por.pdf >. Acesso em: 5 maio. 2016.

PAUL, Patrick. Saúde e Transdisciplinaridade: a importância da subjetividade nos cuidados médicos. Tradução de Marly Segreto. São Paulo: EDUSP, 2013.

PINEAU, Gaston. Las reflexiones sobre las prácticas: el corazón de la vuelta reflexiva. In: ESPINOZA, Ana Cecília Martínez; GALVANI, Pascal (Coord.). Transdisciplinariedad y formación universitária. Puerto Vallarta: CEUArkos, 2014. p. 91-114.

SCHERRE, Paula Pereira. Curso de formação dos educadores para a cidadania: tecendo uma metodologia transdisciplinar. In: CONGRESSO NACIONAL DE EDUCAÇÃO EDUCERE, 11., 2013, Curitiba: Pontifícia Universidade Católica do Paraná. Anais do... Curitiba: PUCPR, p. 9284-9301. Disponível em: <http://educere.bruc.com.br/arquivo/ pdf2013/7709_5694.pdf>. Acesso em: 22 nov. 2014.

SCHERRE, Paula Pereira. E quando pesquisador e pesquisado são a mesma pessoa? Reflexões epistemo-metodológicas a luz da Complexidade e da Transdisciplinaridade. Revista Terceiro Incluído: Transdisciplinaridade e Educação Ambiental. Universidade Federal de Goiás, v. 5, n. 1, 2015a, p. 263-286. Disponível em: 〈http://www.revistas. ufg.br/index.php/teri/issue/view/1593/showToc>. Acesso em: 9 maio. 2016.

SCHERRE, Paula Pereira. (Trans)formação do ser docente-pesquisador: reconstrução da matriz pedagógica-pesquisadora à luz da Complexidade e da Transdisciplinaridade. 2015b. 380 folhas. Tese (Doutorado em Educação) - Universidade Católica de Brasília, Brasília, 2015b. Disponível em: <http://www.bdtd.ucb.br/tede/tde busca/arquivo.php? codArquivo=2385> . Acesso em: 5 maio. 2016.

UNESCO. Repensar a educação: rumo a um bem comum mundial?. Brasília: UNESCO Brasil, 2016. Disponível em: <http://unesdoc.unesco.org/images/0024/002446/244670POR. pdf>. Acesso em: 2 jun. 2016. 